The Radial Velocities of Nebula.-Prof. Campbell, writing to the Astronomische Nachrichten (No. 4508), urges that as many radial velocities of nebula should be determined as is possible.

Keeler's observations of the radial velocities of twelve planetary nebulæ show that these objects probably have very high actual velocities, something of the order of $25 \mathrm{~km}$. per second. On the other hand, observations of the Orion nebula, and others, indicate that these extended nebula have very low radial velocities, or are at rest relatively to the stars of our system. If these facts can be accepted as a generalisation, many problems connected with stellar evolution are opened up. For example, it is suggested that the extended, amorphous nebulæ are masses of primordial substance antecedent to the stellar state, whereas the quickly moving planetary, or condensed, nebulæ are the results of collisions, or near approaches, \&c., of rapidly moving aged stars. Some support is given to this suggestion by the observation that helium (early) stars show but small radial velocities $(6 \mathrm{~km}$.), whereas the older, reddish stars give much higher ( 16 or $17 \mathrm{~km}$.) velocities.

The Interferometer in the Study of Nebulaz.-In the June number of The Astrophysical Journal (vol. xxxiii., No. 5, p. 406) MM. Fabry and Buisson describe an apparatus they have employed in the spectroscopic study of nebulæ. This apparatus is compact and light, and can readily be attached to any telescope of sufficient aperture for the work. They have used it with the Marseilles refractor of io inches $(26 \mathrm{~cm}$.) aperture and ro feet (3.I metres) focal length, and have secured useful observations of the Orion nebula; but a reflector of large relative aperture would be much better for the work, because of its achromatism.

The method is capable of giving very accurate measures for the wave-lengths of the different nebula lines, and, therefore, using the hydrogen lines should give the radial velocity with great precision. By finding the variations of wave-length from one part of the nebula to another, the circulatory movements of the gas might be determined.

The Rotation of Stars about their Axes.-In a note published in No. 7, vol. lxxi., of the Monthly Notices p. 578), Prof. George Forbes makes an interesting suggestion on the possibility of determining the rotation of stars about their axes and the direction of the axes. In the ease of the sun this rotation causes a displacement of the lines in the limb spectra, which in the case of the integrated light of the stars would become a broadening of the lines. But if the star is an Algol variable the light from each limb is periodically arrested by the eclipsing satellite, and the spectral lines should then show broadening on one side only. When the other end of the bright star's equator is eclipsed, broadening on the other side of the line would tesult. Relatively this would amount to a periodical displacement of the lines about a mean position, such as has been observed in some cases, and a measure of the displacement might provide material from which the direction of the star's axis and the velocity of equatorial regions of the star could be approximately deduced.

The Tails of Comet rgioa.-From Prof. K. Pokrowski, of the Dorpat Observatory, we have received an interesting monograph dealing exhaustively with the several tails of comet rgroa. From fifty-nine observations made by various observers-many of which were recorded in these columns--Prof. Pokrowski determines the positions of different points in the tails, and then calculates the time at which the matter forming them was ejected and the value of the repulsive force which drove them away from the nucleus. He thus finds that the chief tail conforms to Bredichin's second type, the repulsive action being about equal to the gravitational attraction; the western branch of the tail was probably ejected, under rather greater repulsive force, from the nucleus about January 18.

The second, smaller tail, belongs to the third type, being formed under a repulsive force considerably less than the gravitational repulsion by particles which left the nucleus about January $x 6$. The anomalous tail, directed towards the sun, is likened to those of comets 1844 III., I862 III., and 1882 II., where the particles left the nucleus with a very small velocity, in this case about $0.5 \mathrm{~km}$. per second.

\section{CONFERENCE ON EDUCATION AND TRAINING OF ENGINEERS}

THIS conference, organised by the Institution of Civil Engineers, held its meetings at the rooms of the institution on June 28 and 29, under the presidency of $\mathrm{Mr}$. Alexander Siemens. The subjects were discussed under three sections, general education, scientific training, and practical training, the chairmen of these being respectively Mr. Anthony G. Lyster, Dr. W. C. Unwin, and Mr. R. Elliott-Cooper. There were very large attendances at all of the meetings.

In opening the conference, the president stated that the council of the institution had endeavoured to define the scope of discussion by declaring that its object was to consider the methods of preparation to be adopted by those who contemplate entering the engineering profession in compliance with conditions laid down by the by-laws for election into the institution. In addition to a sound general education, to a competent knowledge of science and to practical training, there is the necessity common to all professions, which Prof. Max Müller defines thus :"... No science and no art have long prospered and flourished among us, unless they were in some way subservient to the practical interests of society ... that interest depends on the practical advantages which society at large derives from these scientific studies." This principle may be expressed by saying that a young engineer should be educated so as to become a dividend-earner for his employer, for this is the most trustwortily indication of his merit. He should possess some knowledge of business methods and of law, and he will find one or more modern languages very useful in obtaining remunerative emplovment. No definite resolutions would be taken on the subjects under discussion, as the object of the conference is rather to form opinion than to arrive at and to record definite conclusions.

Sir Wm. White directed attention to the danger of too much devotion to the theoretical side. At one time training in engineering science could scarcely be obtained, but there was a modern tendency to go too far in the other direction at the expense of the practical side of the engineer's training. The evils of coaching for examination purposes were also pointed out by the same speaker. Sir J. Wolfe Barry justified the introduction of admission to the institution by examination, and considered that in the engineer's course of training the general education of an accomplished gentleman should not be lost sight of.

Mr. Anthony G. Lyster considered that education, to be of real value, should not only furnish information and knowledge, but should also train and expand the intelligence and develop that type of character which fits a man to lead the best and most useful life. The demand for special training for the engineer becomes increasingly urgent, and unless he is to be debarred from our universities or public schools, it behoves the authorities to bring their educational standards into line with modern requirements. There is no desire that members of the engineering profession should be engineers and nothing else; on the contrary, every opportunity should be given to the best type of man that the university and public school can produce to start with the best intellectual equipment as an engineer.

In the general education section, Dr. James Gow, headmaster of Westminster School, opened the discussion on literary education and engineering by stating that his experience as examiner in Latin for the institution showed that Latin is seldom included in the preliminary education of an engineer, or that boys who intend to be engineers pay little attention to this subject. It is probable that, where Latin is neglected, no very close study is given to any other language. $\mathrm{He}$ did not contend that literary studies are of any direct or immediate use to the engineer: his work must be largely deductive and mathematical, on which a literary education has no bearing. But presumably there are occasions when he is called upon to make use of chemistry or geology, or some other deductive science, and he is not properly equipped unless he has a fair knowledge of these sciences. Now it is notorious, at least to schoolmasters, that a boy who passes from the classical side to the modern side of a school has an immense advantage in inductive science over those who

NO. 2175 , VOL. 87] 
have been educated entirely on modern lines. Latin, as taught with grammar and dictionary, is inductive science almost in the abstract. Again, the engineer is doubtless often called upon to command a gang of foreign workers. The sooner and the better he learns their language the more easily he will control them and direct their labour. The language may be wholly alien to any that is spoken in Europe, yet the necessary elements of language must always be the same. It is undoubtedly the business of the engineer to understand contracts, and to give and receive orders accordingly. These transactions require a careful and exact appreciation of words by whomsoever used. It is too often forgotten that the whole profession of lawyers lives, in the main, on the inability of other people either to say what they mean or to understand what is said to them. Dr. Gow suspects that the time is at hand when it will be advantageous to the engineer to mingle the utile with the dulce, to discern not only what is mathematically possible, but also what is artistically impossible, not only what is cheap, but also what is nasty. For this purpose some general culture is necessary, such as makes a man liberal in mind and sympathetic to the common run of his fellows. Dr. Gow considers that the best plan is to give a boy a general education, mainly literary, up to sixteen years of age, and at that point to watch him closely and put him to what he wants to learn. If he is clever he will be successful; if he is not clever he will, at least, be happy and proud of his calling.

Prof. Silvanus P. Thompson initiated a discussion on the extent to which mathematical and scientific subjects should share with other subjects of literate education the attention of schoolboys who intend to enter later the engineering profession. In the present chaos of secondary education, the schools of the type which chiefly furnishes boys to the engineering profession are almost wholly destitute of any organisation adapted to that end. Not one, so far as the speaker knew, has any definite educational goal to set before the majority of its boys. In general, schoolmasters devote their energies to preparing a few scholarship candidates, and have no definite educational aim whatever for the bulk of the boys. Until this hopeless state of things is radically altered, and until the goodness or badness of a school is adjudged, not by the triumphs of a few, but by the proportion of all its scholars whom it brings to a maturity test, British education will continue to be in a bad way. In all German secondary schools there is a perfectly definite goal before every boy in the school. Before he reaches the topmost class he will have to pass the Einjährige examination, or pass out disgraced. Three years later, if he passes the Abiturient examination, the way is open for him to any university and to any professional career; otherwise he is marked as unfit for professional life. Here, with us, the State (save in Scotland) has not yet organised the secondary schools. Each university wastes its energies over holding matriculations and the like. Almost all the professional bodies hold amateur matriculations or preliminary examinations of their own. The result, educationally, is muddle, waste, inefficiency. The schoolmasters, in despair at the multitude of twenty conflicting matriculations, fix upon none, and let chaos work.

Prof. Thompson is in agreement with the recommendations of the report of the committee of the Institution of Civil Engineers, given $5 \frac{1}{2}$ years ago, on the studentship examination. These briefly are:-(I) specialisation at school is undesirable; (2) a leaving examination for secondary schools, similar to that in existence in Scotland and in Wales, is desirable throughout the United Kingdom; (3) instruction in mathematics should be by somewhat modified methods; (4) a general knowledge of elementarv physics and chemistry or natural philosophy is preferable to the pursuit in detail of some particular department in science.

At school, the first object of science teaching should be to evoke interest, not to impart the facts or data of science, still less to systematise their rediscovery. All that has its place later. Even the driest subject can be made thoroughly attractive by a live teacher who handles his subiect in a human way. A bad teacher can make even electricity as dull and distasteful a subject as the conjugation of irregular verbs. One difficulty which has been explained by masters of progressive tendencies in seeking to introduce mathematical reforms such as that which has come about in the past few years has been the stupidity of inspectors, who have not yet grasped the importance of the reforms. The benumbing influence of all the older Cambridge traditions is also felt. Bad teaching is responsible more than anything else for distaste for mathematics. A really capable teacher will make his boys enthusiastic over matters that in the hands of others are deadly dull.

The greatest change which has come over the teaching of mathematics is the almost complete disappearance of Euclid. Prof. Thompson is not sure whether the loss is not greater than the gain. The teaching of Euclid was in one respect absolutely invaluable. If approached rightly, after practice in geometrical drawing, the study of Euclid constitutes an unrivalled training in methodical and cogent reasoning. But Euclid is gone, and there has been no satisfactory substitute for it. It is the opinion of Prof. Thompson that boys nowadays are less capable of following a sustained train of thought than they used to be.

In the conflict of subjects, one is apt to lose sight of the fact that training in thinking and in the correct expression of thought is more essential than the study of any particular subject. In all studies--science, mathematics, language, or literature--there should be cultivated precision in the use of words and cogency in modes of thought. These things are vastly more important in the ultimate making of a professional engineer than the acquisition of a hoard of scientific fame. The secondary school must not degenerate into a home of cram.

Sir John Wolfe Barry agreed th Dr. Gow that specialisation should not commence too early. A general training should be given in early life, as it was impossible to attain to such later. His own early training had not been directed towards engineering, and he considered that this had been to his advantage.

Mr. Theodore Reunert, of Johannesburg, hoped that the conference would lay down a definite course of training for engineers. In other professions parents could obtain definite information regarding the course of study and training through which their sons must proceed; in engineering no such information is available.

Dr. W. H. D. Rouse thought that specialisation before sixteen or seventeen was wrong. In his opinion, Prof. Thompson had not spoken too strongly in regard to the evils of examinations. Examinations were generally of an undesirable character, and their continued multiplication was a great evil. Prof. Thompson's remarks about German examinations being conducted by cooperation between the State and the teachers were of value, and he considered that such was the only way that was fair to the teachers.

Mr. W. Whitaker, F.R.S., could not confirm the view that culture could be obtained only in early life. Dr. Gow had emphasised the educational value of literature there was nothing like leather, and he noticed that Dr. Gow was a Doctor of Literature. Mr. Whitaker agreed with Prof. Thompson's remarks on the teaching of Euclid. He believed that English was taught very badly, and that scientific men in this respect were as badly trained as the majority of people, and worse than most.

Dr. R. Mullineux Walmsley thought that the lack of a definite educational aim in England was due to defective public opinion. In this respect matters were much better in Scotland. The statement which had been made that universities had to hold matriculation examinations because they wanted the fees was true, and if the London University gave its examinations up it would be bankrupt - a scandalous state of affairs.

Prof. W. S. Abell considered Euclid to be the basis of the English system of mathematics, and that the Institution of Civil Engineers should insist on its being taught.

Colonel J. E. Capper said that a mechanic might be able to lay a railway, but an engineer, in addition, should be able to say if it was necessary to lay it at all. To answer such questions, a general literary education was necessary.

Mr. T. H. Bailey suggested that Prof. Thompson had missed the aim of public-school life, which was not to turn out professional men, but to give a general grounding and moral training.

Both Dr. Gow and Prof. Thompson in their replies 
agreed on the undesirability of having a rigid examination for all students. But schoolmasters certainly desired the laying down of a general course which might be available for the information of parents.

Prof. Alfred Schwartz opened the question of specialised entrance examinations for university or college courses of study in engineering, and is of opinion that a satisfactory standard of general education should be attained, and should not include specialised subjects germane to engineering science. This examination should admit to all faculties. The secondary-school training of the engineer should be on as liberal lines as possible, since his subsequent training is largely materialistic. What is wanted in the engineering courses is a supply of students with a wide mental outlook, whose faculties have been well trained and evenly developed, and any specialisation in the secondary schools at the expense of this liberal training is to be deprecated.

Mr. J. T. Jackson considered that entrance examinations should be so framed as to be capable of being passed by students of good general education only. His own experience was that men who commenced engineering at an early age were less successful generally than those who commenced at a later age.

Prof. W. C. Unwin considered that some early specialisation was desirable. Boys of eighteen, without such specialisation, had to look forward to three years of study and three years of practical work before being in a position to take responsible posts. This would bring them to twenty-four years of age before they were capable of earning a living. Not much was asked for, but he thought that a boy of eighteen might be expected to be prepared in part for his future career. He did not agree, as the result of his experience at Coopers Hill and at the Central College, with Mr. Jackson's remarks regarding non-success being due to an early start in engineering. Prof. H. J. Spooner pointed out, in regard to mathematical training, that students were now generally given courses in practical mathematics. The result is that few students now took mathematics as a regular study, necessitating much special cramming for mathematical examinations.

In closing the discussion, Mr. B. Hall Blyth said that he thought it would bear some good fruit if it resulted only in the restoration of Euclid to its old place in the schools. He agreed with the many speakers on the dangers of cramming, and thought that the institution, whose own examination was open to the charge, might take these remarks to heart.

Mr. R. Elliott-Cooper, as chairman of the section on practical training, opened the proceedings in this section by saying that it was of importance that all should be agreed, if possible, as to what practical training really means. Real and useful practical training can be obtained only under the actual or commercial conditions which cannot be found in educational establishments. The knowledge which young engineers may obtain from, say, two years in the workshops of a contractor after his college course is completed, should be supplemented by the experience to be gained in an engineer's office. Such experience would include designing, drawing, specifying, and estimating. In a few branches of the profession pupilage does not occupy its former place, but, taking the profession as a whole, inquiry shows that it still holds an important position.

Mr. Alfred F. Yarrow, in dealing with the apportionment of training between practical work and scientific study, took up the social aspect of the question, and gave some suggestions applying to apprentices in or on works far distant from their homes. He was of opinion that a sandwich system of six months in the works and six months at college was desirable. The student living at home during his college term would be under good influences and affectionate surroundings such as were impossible during a lengthy apprenticeship away from home. London colleges especially should so arrange their courses as to render this system available for their students. Further, some member of the staff in the works should be looked upon as an adviser to the apprentices. He should be accessible at all times, and should make a point of interviewing each lad at least once in three months and ascertain if he could be of service to him. He should also keep in touch with the work of lads attending evening NO. 2 I 75 , VOL. 87$]$ classes by personal visits to the local technical schools. This system is of advantage both to apprentices and emplovers, and would enable the latter to select wisely those apprentices whom it is desirable to retain after the termination of their apprenticeship. It is a notorious fact that employers have often lost the services of many capable men through being ignorant of the talent that has passed through their works.

Mr. William H. Allen, dealing with the case of a student determining to go both to college and to works, was of the opinion that the college course should be taken first. In his experience this is the order of procedure in which will be found the best chance of success. As regards how much study should be undertaken by a pupi during the period of his practical training, Mr. Allen thought that, if a young man does his duty conscientiously in the works from 6 a.m. to 6 p.m., he will find that as much as his health can stand, without burdening it by further serious study at night. A period of training in the workshops extending over three years is desirable, and should not be specialised too greatly.

Mr. F. E. Robertson referred to the deficiencies in the knowledge of elementary science in young men trained in locomotive works who present themselves to him for examination for posts in India. Prof. Arnold said that his experience had been quite different, and cited the case of the Midland Railway, who handle the training of their apprentices in an excellent manner. Prof. Arnold regretted the modern drifting apart of the engineering side and the metallurgical side in the training of engineers. Mr. E. R. Dolby thought that too much was being attempted in the training of an engineer, and that better results would be obtained by subdivision, as is done in the architectural profession.

Mr. E. Benedict thought that people who accepted premiums should also accept responsibility, and advocated the deputing of someone to look after apprentices.

Prof. E. G. Coker regretted the loss of engineering establishments in London, and favoured a six months sandwich system. Prof. W. E. Dalby found that teaching was much easier to workshop-trained youths than to others. The sandwich system is best if it can be worked: he had asked works to take pupils on this system, but had not always met with success. The premium question presented a difficulty.

$\mathrm{Mr}$.W. B. Worthington, dealing with the question of training in the engineer's office, said that engineering as an art and profession is based upon the matter of design. However sood a man's training and experience on constructional works or in the shops may be, it will not, without experience in the engineer's office, make him a civil engineer, although it may make him a good mechanic or contractor.

Dr. W. C. Unwin presided over a joint meeting of the sections on scientific and practical training, and in opening the proceedings gave a carefully considered statement of the relations between the employers and college-trained youths. This is printed in full elsewhere in the present issue.

Dealing with the relation of engineering employers and colleges from the point of view of the practical training of college students, Prof. J. E. Petavel thought that the employer can cooperate in the educational work of the university by a frank and friendly criticism of the methods adopted, and by offering to take college graduates on a six months' trial.

Mr. James W. Horne directed attention to the cases of engineering firms who have developed a keen interest in the better education of those apprentices who start at sixteen years of age. Every encouragement is given to attend evening classes, and several give facilities for attending college on one or two afternoons a week. By these means many have reached a standard of education which enables them to proceed to a college for two or three years' courses. Such apprentices are a valuable asset to the nation.

Mr. Alexander Siemens did not consider it possible to allow apprentices off on one or two afternoons a week. $\mathrm{Mr}$. Hall Blyth referred to the mistaken idea which some engineering professors have that their students are ready, on leaving college, immediately to take a responsible place in the works. Sir $\mathrm{W} / \mathrm{m}$. White directed attention to the 
many cases of swelled-head in college graduates, a matter which interferes with their employment in a good many instances. Reference was also made in the discussion to the plan followed at Bristol, whereby unsuitable students are advised, through their parents, to withdraw from college at the earliest possible moment. (It may be said here that other colleges also follow this procedure.)

Prof. Archibald Barr advocated a six months' sandwich systern, and pleaded that engineering institutions should allow a wide latitude in the systems of training that they will recognise. Prof. Henry Louis did not think that the six months' sandwich system is satisfactory, and suggested the course followed by mining students of three years' college followed by three years' practical work.

Mr. John A. Brodie had little sympathy with those who think it necessary that young engineers should work a reduced number of hours in the workshop in order to enable a greater time being given to study. If the youths of our day cannot or will not stand the strain of the severe training which has given good results in the past, they will probably have to take a position behind those who are prepared to do so. There are other lines of life in which young men can acquire both money and position more easily and quickly than in the engineering profession.

Prof. Stephen M. Dixon opened the subject of the value of a university degree in engineering science in relation to professional competence. There is a feeling in some quarters that the university graduate is rather in the way in an engineer's office. Matters, however, in this respect are improving. When engineering firms recognise the advantage of having assistants thoroughly trained in the principles underlying practice, and whose training also specially fits them for adopting new ideas rapidly, they will be only too glad to cooperate with the universities in completing the education of the engineer.

In dealing with the same subject, Prof. Charles F. Jenkin said that an engineering degree may be looked at in three lights: as a guarantee that the holder has had the best theoretical training and has profited to some extent thereby; as the final step in that type of liberal education at the universities of which England is justly proud; as a broad basis on which State recognition of the engineering profession may be founded.

Prof. Fleming attacked vigorously the whole system of degree examinations as being wrong and as liable to pass candidates whose knowledge was of a very scrappy nature, a view which was promptiv controverted by another speaker, who said that he had five degree men in his London office and was entirely satisfied with the results. The same speaker had a good word to say for men who had been trained in evening classes; he was of opinion that swelled-head accounted for some failures in graduates, but that these men were of use after they had been got in hand.

Profs. Dalby, Hopkinson, and Goodman dealt with the subject of the position and uses of engineering laboratories in relation to education at college. All agree that small units are of more service in the work of education than the very large pieces of apparatus-steam engines of large power and the like-which used to find favour.

In closing the conference, Mr. Alexander Siemens suggested that schoolmasters should try to agree on a common svllabus for leaving examinations. University teaching should be scientific and wide in its scope; the training of the mind is all-essential. He was of opinion that practical training should begin by a vear in the workshops to be followed by the college course, and then back to the workshops again for completion of the practical training.

TOTAL SOLAR ECLIPSE, TASMANIA, MAY, 19 Io. $^{1}$

I $N$ a short introduction the author and leader of the expedition explains his motive in publishing in full this account of a solar eclipse expedition which was, unfortunately, unsuccessful in its main obiect. The site chosen for the camp was in very wild, mountainous

1 Report of the Solar Eclipse Expedition to Port Davey, Tasmania, May, rgro. By F. K. McClean and others. Pp. $42+35$ plates. (London Printed by R. Clay and Sons, Ltd. Plate; reproduced by A. E. Dent and Co., Ltd., 19ro.)

NO. 2 I 75 , VOL. 87$]$ country on the southern shores of Tasmania, and in these circumstances it is evident that, going as a private party, exceptional provision had to be made for the many details of equipment, transportation, and maintenance of the observers during the period of preparation for the observations. It was with the hope of giving useful information on these questions that the author decided to present the $\log$ of his journey at length.

In chapter i. a very interesting account is given of the general preparations for the eclipse, the prospecting journeys for selection of site, that finally occupied being on Hixson Point, Port Davey. After this was settled, some time was occupied in arranging for and purchasing tents, camp equipment, food and drink, and other details necessary for nine persons during a stay of one month. At the camp, nothing was available for food except fish, wallaby, wombats, and kangaroos. A complete list is given of the details of the equipment and stores; in the case of foodstuffs, \&c., both the quantities taken out and the amount unused are given, from which future pioneers in this class of work may learn wisdom; for instance, lime juice was evidently not the beverage most sought after, as out of eighteen bottles taken, thirteen are recorded as unused. A very useful item is the actual cost of the expedition, reckoned from Hobart out to Port Davey, the stay there, and back to Melbourne-347l.

As a more or less detailed account of the instruments taken out for the work on the eclipse has already appeared in Nature, it is only necessary here to say that, in spite of most trying and tempestuous weather, the whole apparatus was adjusted ready for the eclipse time. Details of the work involved for each section are given, with very clear photographic illustrations of the progress and methods adopted in transporting the heavy cases over the difficult ground from the shore to the camp site. Provision had been made for obtaining photographs of the corona with telescopes of various apertures and focal lengths, and for the spectrum of the chromosphere and corona with a powerful concave grating spectrograph.

Included is a report on the observations made by J. Brooks for the determination of the astronomical position of the site, and a description of the corona photographs obtained by another party at Queenstown. After examination of these plates, on which the diameter of the moon's image is $4.4 \mathrm{~mm}$., Mr. W. H. Wesley reports that the extensions of the corona were very small, in no part reaching beyond one quarter the moon's diameter from the limb. On a plate submitted by another observer, with a smaller image still, $1.5 \mathrm{~mm}$., the extensions reach about one diameter. The most striking feature was a wide rift, fairly symmetrical with the South Pole, extending for nearly $50^{\circ}$ along the limb. There was also a long ray of synclinal character on the east of this southern rift.

The form of the corona appears to be of the type associated with the period intermediate between the maximum and minimum of solar activity.

The volume is illustrated by thirty-five excellent photographic reproductions showing the interior of Port Davey Harbour, incidents in the transportation and erection of the various instruments, a scrub fire which very nearly destroyed the camp, and the photographs of the corona obtained at Queenstown by the Rev. L. S. Macdougall and Mr. J. Booton.

Charles P. Butler.

\section{THE CAMBRIDGE ANTHROPOLOGICAL}

\section{EXPEDITION TO WESTERN AUSTRALIA.}

I $\mathrm{N}$ the early part of last year plans were made for an anthropological expedition to Western Australia, and Mr. A. R. Brown, Fellow of Trinity College, Cambridge, who had been re-elected to the Anthony Wilkin studentship, was appointed leader, the main object of the expedition being to study the social organisation and magicoreligious beliefs and observances of the natives. Mr. Brown left England at the end of July, igro. Soon after his arrival in Perth, mainly through the instrumentality of Mrs. D. M. Bates, a donation of Ioool. was made to the expedition by Mr. Samuel P. Mackay of that State. This 